\begin{tabular}{ll}
\hline \hline MINING AND METALLURGY INSTITUTE BOR & ISSN: 2334-8836 (Štampano izdanje) \\
UDK: 622 & ISSN: 2406-1395 (Online) \\
\hline \hline
\end{tabular}

Daniel Kržanović, Nenad Vušovic ***, Milenko Ljubojev ${ }^{*}$

\title{
SELECTION OF THE OPTIMUM PUSHBACKS IN A LONG-TERM PLANNING PROCESS OF THE OPEN PIT - A CONDITION FOR MAXIMIZATION THE NET PRESENT VALUE: CASE STUDY: THE OPEN PIT VELIKI KRIVELJ, SERBIA***
}

\begin{abstract}
Defining the pushbacks at the open pit is one of the most important planning activities. Designing the pushbacks is the first step in a long-term planning of production at the open pit where the production is planned. Despite the existence of a large number of software, used for different mathematical algorithms for optimization the open pits, a role of mining engineers is still a key one in development the mining plans.

The work presents the results of conducted impact analysis of selection the optimum pushbacks on the project economy. Based on the results, the importance of correct selection of pushbacks can be concluded for achieving the basic goal of the mining operation - the Net Present Value Maximization $(N P V)$.
\end{abstract}

Keywords: optimal pushbacks, open pit long-term planning, maximization of Net Present Value

\section{INTRODUCTION}

Maximizing the net present value of a project is the usual objective of mine planning. Achieving this objective through the optimization of planning process has been the subject of significant research and development over the last fifty years, and new developments continue in the field.

Despite advances in the available algorithms, procedures, and software in the surface mine planning, the role of the human planner is still paramount. The mine plan is developed by the mine planners. Mine planning interacts with a variety of other planning areas, and is influenced by corporate objectives and constrained by regulatory requirements.

A consequence of not having an understanding of interdependencies in the planning system may be a plan that achieves a local goal at the expense of the broader plan objectives [1]. Hence, the application of experience and judgment in selecting the planning inputs is considered to be as important to producing the improved results as the software or optimization algorithms themselves [2, 3].

\footnotetext{
* Mining and Metallurgy Institute Bor, e-mail: daniel.krzanovic@irmbor.co.rs ** University of Belgrade, Technical Faculty in Bor

*** The work is the result of the Project TR 33038 "Improvement the Technology of Copper Ore Mining and Processing with Monitoring of Living and Working Environment in RTB Bor Group", funded by the Ministry of Education, Science and Technological Development of the Republic of Serbia
} 
Strategic mine planning requires, at a minimum, a definition of objective(s) of the study, a block model containing information on block characteristics grade(s), density, process recovery, etc.), an understanding of geotechnical constraints (allowable pit slopes), and estimates of commodity sale prices, mining and process operating costs, and capital costs.

The block model is the basis of modern open pit mine planning. A block model is a regularized, three dimensional array of blocks used to represent the properties and characteristics of the ore body. The raster representation of the ore body is beneficial to analysis using the computerized techniques, and has resulted in development a variety of algorithms and software packages that use a discretization of the ore body into a block model as their basis.

The focus of such analysis is on pits created at commodity prices below the longterm expected price, and even below the worst-case price. These pits help the planner to identify the highest value per ton portions of the ore body and thus guide the mining sequence [4].

A well-known early contribution to this field was made by Lerchs and Grossmann [5], who presented a graph-theoretic algorithm for determining the final contour of the open pit, known as the ultimate pit so that the total profit from the mine is maximized.

As a rule, the planning engineers are not specially trained for this type of work, but it is necessary to have a large amount of professional experience, as well as a significant knowledge of specialized software tools necessary for performing the precise and efficient analysis of design solutions. The importance of experience in planning in the mining projects is especially evident when taking into account the nature of the input parameters necessary for carrying out numerous analyses. Namely, the values of many parameters are not known or uncertain, or they move in a narrower or wider context. In such cases, the experience plays a key role in the planning process $[6,7,8,9$, 10]. Due to the uncertain nature of input parameters, as well as a great reliance on the empirical making conclu-sions, the planning process is, as a rule, iterative and longlasting.

There is no mathematical algorithm that will precisely determine the number of required development phases and correctly perform distribution of reserves according to these phases. Bearing this in mind, it is particularly focused that the engineering experience plays a major role in division of the open pit to the exploitation phases, and that this activity is often of an iterative character [11].

\section{OPEN PIT OPTIMIZATION AND PUSHBACK SELECTION}

Optimization of the open pit implies the obtaining of possible open pit contour on the basis of a deposit block model, which has an economic value, and which can be calculated. The concept of a possible open pit contour means the open pit contour with maximum inclination of the general slope, formed after drawing the transport routes and safety berms, which meets the stability criteria.

Figure 1 shows the NPV - tonnage graph on the basis of which the Whittle process finds an optimum excavation limit and pushbacks. The graph shows the achieved NPV, as well as the quantities of ore and waste for each nested pit. 


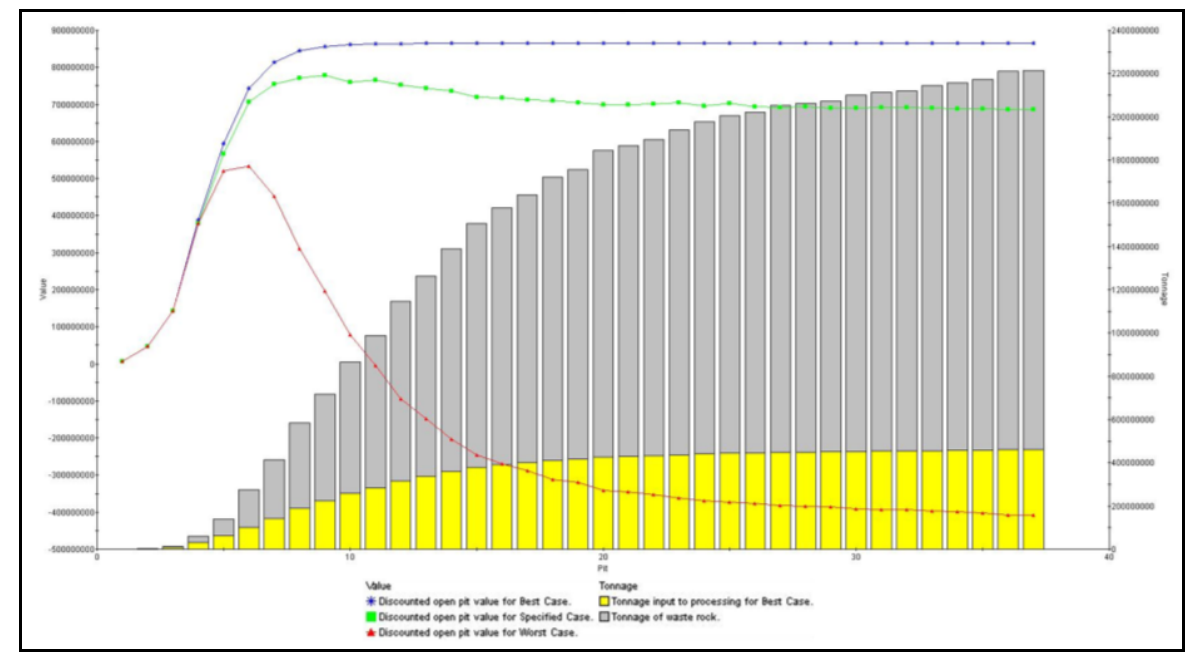

Figure 1 A typical NPV tonnage graph by the Whittle method [12]

The NPV curves for the best and worst case indicate the upper and lower limit values that can be achieved [13].

In this paper, the optimization of the open pit limit and excavation dynamics was carried out using the Whittle software. The Whittle process is based on a rapid implementation of the Lerchs-Grossmann (LG) series of algorithm. This algorithm gives the mathematically optimum final limit of the open pit, when the criterion for optimization is the maximum undiscounted cash flow. The process selects the optimal final limit for the best and worst case of mining excavation plans for which the NPV curves are obtained. In this way, a wide range of possible mines is generated, among which an engineer chooses an optimal mine, which once again confirms that the engineer still has an indispensable role in designing despite a strong development of software and computer equipment [14].

In addition to identifying the optimum pit limit, the pit limit analysis is also used to identify a series of nested pits within the final pit limit. The purpose of these nested pits is to establish a transition from the most profitable material (highest value per unit mined) in the pit to the least profitable or break-even material, which occurs at the pit limit. This understanding will aid the planner in selecting where to begin mining, and in what sequence to mine the pit out in order to produce the highest NPV from the material within the final pit limit.

Pushbacks are nothing more than a sequence of pit limits based on the alternative economic scenarios. Simply put, pushbacks describe how a pit will expand as the value of the recovered mineral increases. The progression of pushbacks or nested pit shells roughly corresponds to the optimal evolution of the mine over time. The underlying factor in design of the pushbacks is to generate a series of nested pits that conforms to not only the minimum required pushback width, but provide the highest dollar value for a particular pit size.

Pushbacks play a very important role in the open pit mine design and optimization. Production scheduling is based on the underling pushback mine sequencing which is widely used for a long-term production planning. The design of pushbacks for ease sequencing and scheduling should be governed by the optimized pushbacks which yield schedules with the highest NPV possible. 
Most open pits are mined in a series of pushbacks. An initial mining pit is established within the bounds of the final pit. The initial pit is then expanded in pushbacks. The order in which the pit expands is the mining sequence. The specific time at which a given block is mined will be determined by the schedule, established during later planning. The initial pit contains high value material (higher than average grade and/or lower than average stripping requirements). Mining a smaller, high value pit first normally reduces the amount of waste that must be mined to access ore. If the grade of material is higher than the pit average, a higher value per ton of ore will result in the initial mill feed. These two factors combine to increase the NPV by realizing the larger profits earlier in the mine life.

An illustration of the impact of using pushbacks is presented by [15], and is commonly reproduced in the literature. For the section shown in Figure 2, a pit limit analysis is undertaken. Eight pit shells are generated. The mine can be developed to the pit 5 wall using two extreme approaches: the 'best case' or highest NPV sequence, and the 'worst case' or lowest NPV sequence.
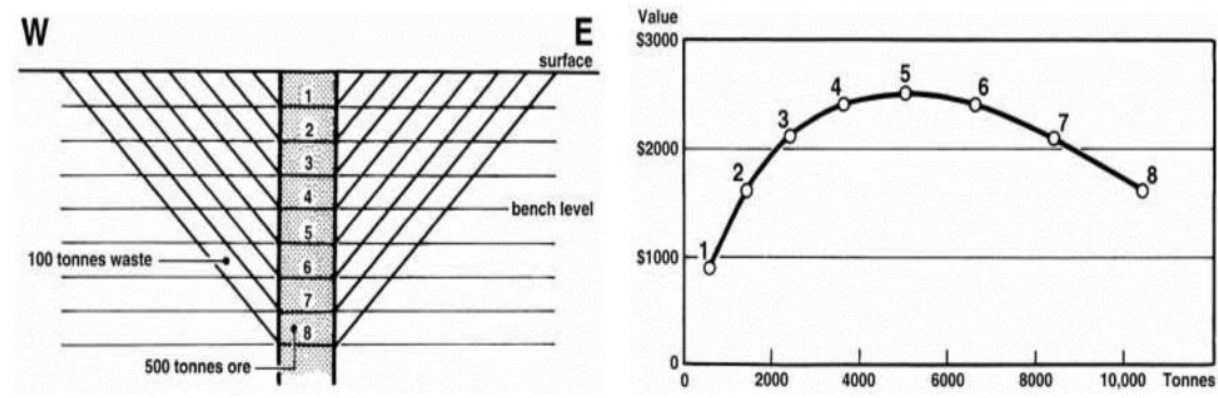

Figure 2 Pushbacks and mine sequencing [15]

The best case sequence requires mining of the nested pits sequentially. A schedule which seeks to balance ore and waste mining was developed for the pit shells in Figure 2 , and discounting was applied to the block values. As indicated by the tones-value curve in Figure 2, pit five is the highest value pit given the assumed cost and price inputs.

In the optimization process of excavation dynamics, the simulation and Discounted Cash Flow Analysis (DCF) are performed in order to obtain the most favorable variant, i.e. determine the number of phases that affect maximization of the net present value in a long-term planning of the open pits. The analysis is based on the Milawa algorithm, which is specifically designed to optimize the excavation dynamics of the long-term exploitation planning strategy.

The Net Present Value is calculated by discounting the estimated annual cash flows at the present time using a discount rate, which represents the investment risk:

$$
\begin{gathered}
\text { Net Present Value }(\text { NPV })= \\
=\sum_{t=0}^{W} \frac{\text { Cash Flow }(C F)}{\left(1+\mathrm{k}^{\mathrm{t}}\right.}
\end{gathered}
$$

where:

$k$-discount rate

$t$ - number of years

The significance of a correct selection of pushbacks in the planning of open pits is seen in the case of the open pit Veliki Krivelj where the copper ore is mined. 


\section{CASE STUDY}

The copper deposit Veliki Krivelj, located about $3 \mathrm{~km}$ by the airline north of the town of Bor, has the primary role in the copper production of copper in the Mining Smelter Basin Bor Group (RTB Bor Group).

Considering that it is a deposit with a low mean metal content in the ore, which amounts to $0.318 \%$ in the total geological reserves, therefore the application of a modern software tool for strategic planning and optimization of the deposit Whittle dand software for construction of the open pit Gems is of exceptional importance for ra- tional utilization of the deposit and achievement the maximum profit in exploitation.

The geological reserves of the copper deposit Veliki Krivelj are calculated using the method of mini blocks, dimensions $15 \mathrm{x}$ $15 \times 15 \mathrm{~m}$. The basis for calculating the geological reserves is a digital block model of the deposit formed in the Gems software $[16,17]$. The geostatistic method, used to estimate the metal content in the deposit modeling process is a method of real kriging.

Figure 3 shows a view of three-dimensional block model of $\mathrm{Cu}$ in the deposit Veliki Krivelj.

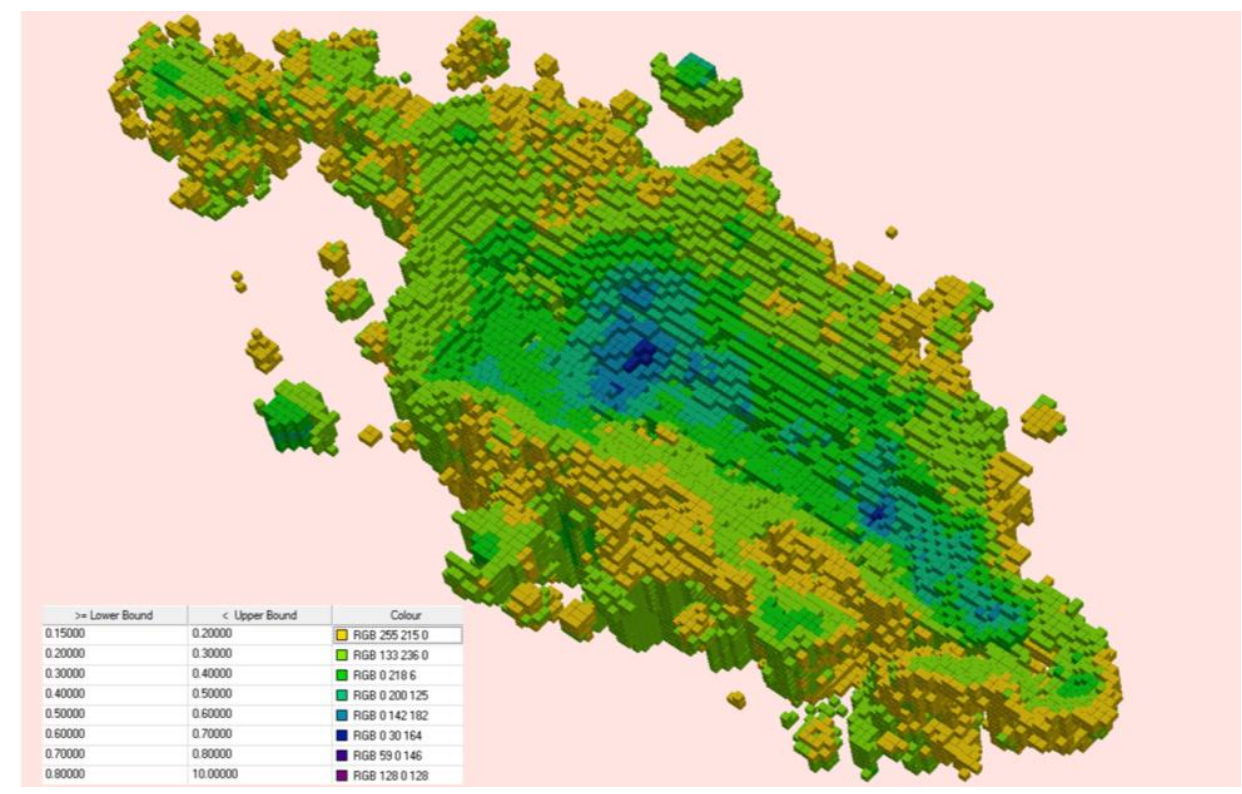

Figure 3 View the 3D block model of the deposit Veliki Krivelj

On the basis of defined block model of the deposit, the optimization of the final contour of the open pit in the Whittle software was performed. The obtained result was the Pit by pit graph (Figure 4), based on which the pushbacks were selected.
The 4 variants were considered in this work, which implied that the DCF analysis was done for each combination of selected pushbacks (Table 1). 
Table 1 Selected pushbacks for analyzed variants

\begin{tabular}{cc}
\hline Variant & Selected pushbacks \\
\hline $\mathbf{1}$ & $9-14-17-19-22$ \\
$\mathbf{2}$ & $9-12-15-20-22$ \\
$\mathbf{3}$ & $10-12-15-19-22$ \\
$\mathbf{4}$ & $10-13-16-19-22$ \\
\hline
\end{tabular}

\section{RESULTS AND DISCUSSION}

The NPV for analyzed variants was obtained in the process of optimization the excavation dynamics.
The results of conducted analysis are shown in the following graphs in Figures 4,5 and 6.

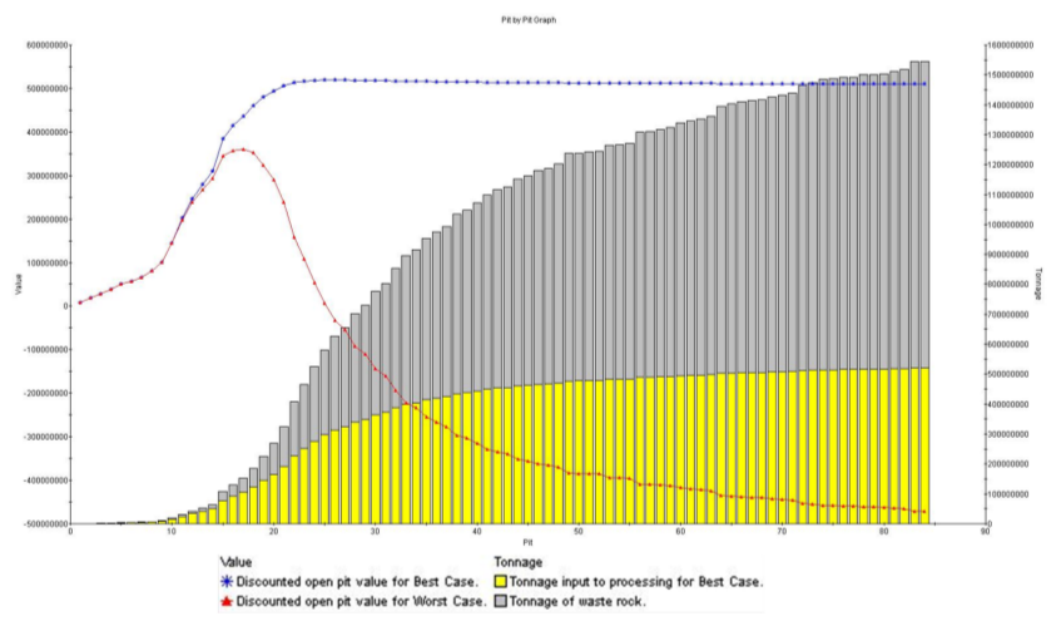

Figure 4 Pit by pit graph

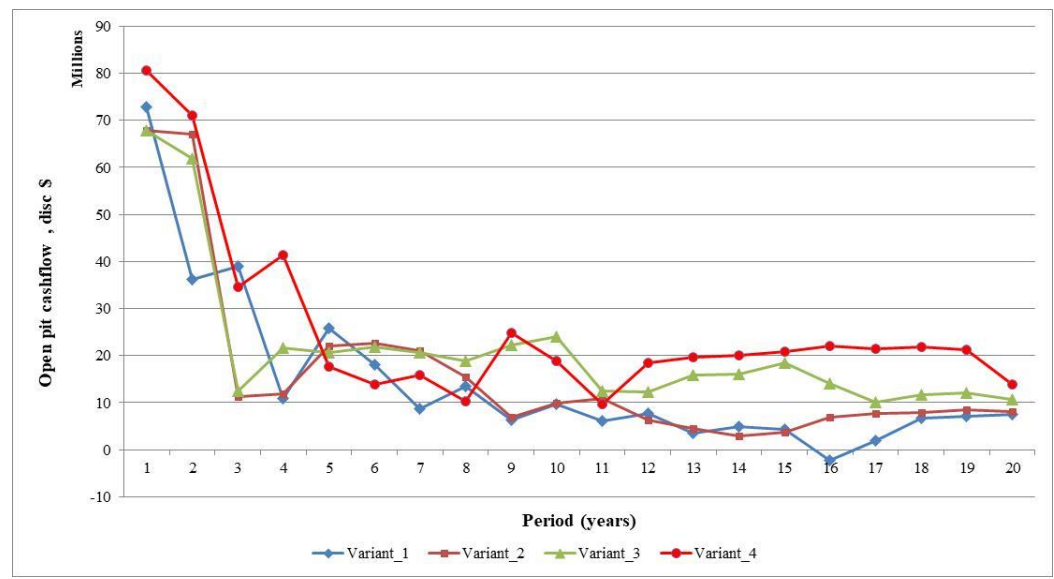

Figure 5 Discounted cashflows for analyzed variants 


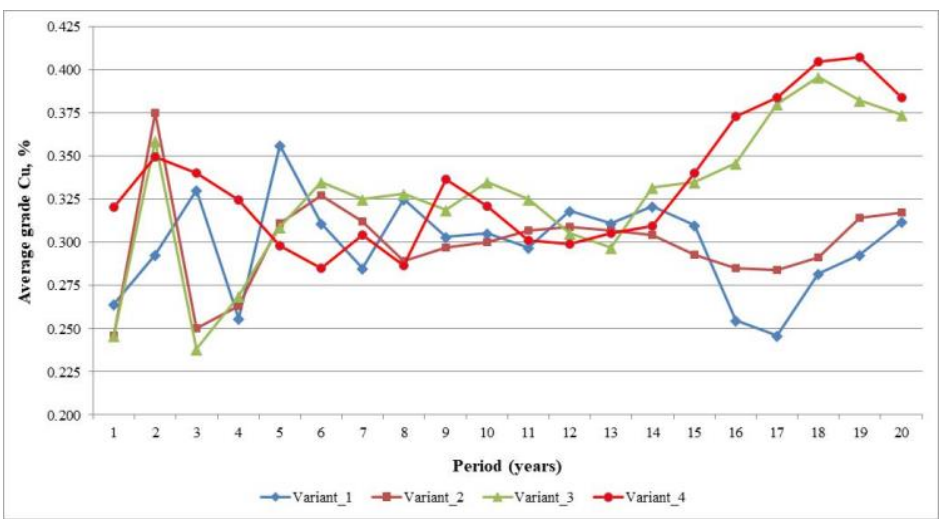

Figure 6 Average grades for analyzed variants

The following can be concluded from the shown graphs:

1) Cash flow for the analyzed Variant 4 in the initial years is considerably higher than the cash flows of the analyzed Variants 1, 2 and 3. The basic reason is that, in the analyzed variants 1, 2 and 3, the pushbacks are selected which are not optimal. Consequently, in the initial years of exploitation, larger quantities of waste are excavated than necessary, and thus the costs of exploitation are higher. Due to application the discount factor in calculating the maximum values of NPV according to analyzed variants, the results shown in Table 2 are obtained.

2) The higher average copper content in the ore in the initial years of exploitation is one of the most important factors leading to maximization the NPV value, which is the case for Variant 4.

Table 2 Max. NPV values for analyzed variants

\begin{tabular}{lllll}
\hline & Variant_1 & Variant_2 & Variant_3 & Variant_4 \\
\hline Open pit cashflow \$ disc & $356,653,607$ & $369,341,333$ & $429,523,617$ & $498,575,975$ \\
\hline
\end{tabular}

\section{CONCLUSION}

Nowadays, several algorithms for optimization the open pits have been developed, which are incorporated into the modern software packages. Nevertheless, a successful long-term exploitation plan still depends on the knowledge and experience of a mining engineer. First of all, it means that an experienced mining engineer can form a rough image and idea of division into pushbacks if he first introduced well the basic geological characteristics of the exploitation reserves (structure, shape, quality assignment, amount of overburden in certain parts).
Also, a planner must be guided by a series of constraints, and above all that the overburden coefficient is within the acceptable limits for all pushbacks, and that the quality assignment according to pushbacks should be within acceptable frames, so that the qualitative conditions can be fulfilled at any time be fulfilled by the exploitation.

On the basis of conducted analysis on a real case - the open pit Veliki Krivelj - it is shown that the errors in selection of pushbacks can have the significant consequences on the business economy of the mining company. 


\section{REFERENCES}

[1] Whittle, J., Long-term scheduling. Proceedings of the $35^{\text {th }}$ International Symposium: Application of Computers and Operations Research in the Mineral Industry. Wollongong: The Australasian Institute of Mining and Metallurgy, 2011, pp. 76-80.

[2] King, B., Optimal Mining Practice in Strategic Planning. Journal of Mining Science, 47(2), 2011, pp. 247-253

[3] Kear, R., Strategic and Tactical Mine Planning Components. Journal of the South African Institute of Mining and Metallurgy, 106, 2006, pp. 93-96.

[4] Ursula Thorley, Open Pit Mine Planning: Analysis and System Modeling of Conventional and Oil Sands Applications, Doctoral Dissertation, Queen's University Kingston, Ontario, Canada, September, 2012

[5] Lerchs, H. and Grossmann, Optimum Design of the Open Pit Mines, Transactions CIM Bullitin, Vol. 58, 1965, pp. 17-24.

[6] King, B, Optimal Mining Practice in Strategic Planning, Journal of Mining Science, vol. 47, 2011, pp. 247-253.

[7] Smith, L, A Critical Examination of the Methods and Factors Affecting the Selection of an Optimum Production Rate. CIM Bulletin, 1997, vol. 90, pp. 48-54.

[8] McCarthy, P. Setting Plant Capacity. Proceedings Metallurgical Plan Design and Operating Strategies, The Australian Institute of Mining and Metallurgy, 2002.

[9] Hall, B., Short-Term Gain for LongTerm Plan, How Focussing on Tactical Issues can Destroy Long-Term Value, 2nd International Seminar Strategic Versus Tactical Approaches in Mining, Australian Centre for Geomechanics, Perth, 2006, sec. 14, pp. 1-19.

[10] Grobler, F., Elkington, T., \& Rendu, J.-M, Robust decision making-Application to mine planning under price uncertainity, $35^{\text {th }}$ APCOM Symposium, Wollongong, 2011, pp. 371-380
[11] Mathieson G.A, Open Pit Sequencing and Scheduling, First International SME-AIME Fall Meeting, Honolulu, Hawaii, 1982.

[12] Kržanović D., Ljubojev M., Jovanović I., Vušović N., An Analysis the Effects of Changes in Price of Metal and Operating Costs to the Profit in Exploitation the Copper Ore Deposits, A Case Study: Copper Mine Majdanpek, Serbia, Mining and Metallurgy Institute Bor, Mining \& Metallurgy Engineering Bor (No. 3-4, 2017), pp. 51-58.

[13] Wharton C., Add Value to your Mine through Improved Long Term Scheduling, Whittle North American Strategic Mine Planning Conference, Colorado, 2000, pp. 1-13.

[14] Kržanović D., Conić V., Stevanović D., Kolonja B., Vaduvesković J., Long-Term Planning for Open Pits for Mining Sulphide-Oxide Ores in Order to Achieve Maximum Profit, Archives of Mining Sciences, Arch. Min. Sci. 62 (2017), 4, pp. 807-824,

[15] Whittle, J, Open Pit Optimization, Surface Mining, Society for Mining, Metallurgy, and Exploration, Littleton, Co, $2^{\text {nd }}$ Edition, 1990, pp. 470-475.

[16] Kržanović D., Žikić M., Pantović R., Important Improvement Of Utilization the Available Geological Reserves of the South Mining District Deposit in Majdanpek in the New Defined Optimum Contour of the Open Pit Using the Whittle and Gemcom Software, Mining Engineering, Mining and Metallurgy Institute Bor, 2012, pp. 29-36.

[17] Kržanović D., Žikić M., Vaduvesković Z., Innovated Block Model of the Copper Ore Deposit South Mining District-Majdanpek as a Basis for Analysis the Optimum Development of the Open Pit Using the Software Packages Whittle and Gemcom, Mining Engineering, Mining and Metallurgy Institute Bor, 2011, pp. 69-76. 